\title{
EL CORREGIDOR DE INDIOS, LA CORRUPCION Y EL ESTADO VIRREINAL EN PERU (1580-1630)
}

KENNETH J. ANDRIEN *

The Ohio State University

En época reciente, los historiadores han empezado a reexaminar la función del Estado colonial en la dirección de las relaciones políticas, económicas y sociales del Imperio español en América. En el caso del Virreinato del Perú, gran parte del interés se ha centrado sobre la administración de Francisco de Toledo (1569-1582), principal arquitecto de los sistemas administrativo, laboral y fiscal del reino durante los años formativos del siglo xvr. Desde su llegada a Perú en 1569, Francisco de Toledo procuró establecer cierto orden en aquel turbulento virreinato, incrementando el poder del Estado con objeto de reestructurar las relaciones entre españoles y amerindios, y canalizar hacia España el flujo de riqueza económica excedente. Algunos estudios recientes sobre el período de Francisco de Toledo se han apartado del análisis de los cambios legales e institucionales atribuibles al virrey, para fijarse en el impacto socioeconómico de sus reformas ${ }^{1}$. Un aspecto que los historiadores no han tratado todavía con la atención debida, sin embargo, es el papel que desempeñaron el fraude y la incompetencia burocráticos en la evolución general del Estado colonial bajo Francisco de Toledo?.

Las intimidantes dificultades metodológicas que supone el estudio de la importancia del fraude y la incompetencia burocráticos constituyen la principal explicación de esta laguna historiográfica. Las abundantes quejas de los coetáneos, sobre la multiplicación de la corrupción y la mala administración, son difíciles de interpretar para el historiador actual. Con harta frecuencia, semejantes alegatos se nos figuran exagerados o movidos por el interés político. Además, el fraude, el soborno y otras formas de malversación eran gene-

* El autor desea agradecer a John J. Te Paske y Miles Wortman sus útiles comentarios y críticas.

1 Spalding (1975, 1982, 1983); Stern (1982 a).

2 Utilizo las palabras corrupción y fraude con el significado de toda violación consciente de las formas de conducta legalmente prescritas, por parte de los funcionarios públicos, con el fin de favorecer su propio bienestar o el de algún grupo de partidarios. He empleado incompetencia para expresar la renuencia o incapacidad de los funcionarios públicos para cumplir con sus obligaciones legales. 
ralmente operaciones encubiertas, y toda evidencia sólida y cuantificable sobre su incidencia es a menudo fragmentaria y poco fiable. Más aún, los criterios de actuación política en las colonias americanas de España permitían un grado de patronazgo, clientelismo y codicia que hoy se consideraría escandaloso. Por consiguiente, el historiador debe cuidarse de aplicar valores políticos del siglo $\mathrm{xx}$ al análisis de las prácticas burocráticas coloniales. Pese a todo, los historiadores están empezando a comprobar cada vez más claramente que las actividades extralegales, tales como el fraude, ofrecían a las élites y a las comunidades indígenas la oportunidad de alterar, controlar e incluso socavar las directrices del Estado colonial ${ }^{3}$.

Cualquier estudio sobre la incidencia e impacto del fraude y la incompetencia sobre los poderes del Estado colonial en las regiones rurales del virreinato debe centrarse sobre los corregidores de indios. Estos magistrados rurales actuaban como agentes políticos y económicos del Estado, y estaban estrechamente vinculados a la producción y distribución de los recursos locales. Durante su virreinato, Francisco de Toledo empezó a instalar de modo sistemático a estos representantes de la Corona en todo el reino, con el fin de sustituir a los indisciplinados encomenderos en cuestiones de justicia local, comercio y recaudación de impuestos ${ }^{4}$. Ahora bien, ciertos testimonios coetáneos y algunos estudios históricos actuales coinciden en señalar que los corregidores se encontraban entre los funcionarios más corruptos y abusivos de las Indias ${ }^{5}$. En efecto, pese a los repetidos intentos de la Corona por acabar con los excesos más flagrantes de los corregidores, su reputación de venalidad y falta de escrúpulos, perduró hasta que la Corona abolió a fines del siglo xviII, con la introducción del sistema de intendencia ${ }^{6}$.

En los últimos diez años, el amplio uso de las cuentas de la real tesorería en estudios demográficos y económicos de las Indias nos ha proporcionado los datos elementales para poder empezar a medir estadísticamente la importancia general de la corrupción en ciertos corregimientos peruanos ${ }^{7}$. El objeto

${ }^{3}$ En obras anteriores donde se trataba la corrupción política, se tendía a considerar semejantes prácticas como una manifestación de la decadencia imperial. Algunos ejemplos de dichas obras son los siguientes: Borah (1970), pp. 707-726; Parry (1953). Algunos estudios más recientes de tipo revisionista, donde se considera la corrupción como una herramienta política inevitable en los sistemas políticos preindustriales, son: Morse (1964), pp. 123-177; Sarfatti (1966); Phelan (1960), pp. 47-65; Moreno (1967), pp. 308-320; Barbier (1972), pp. 416-435; Schwartz (1970), pp. 715-730; Phelan (1967); Lynch (1969), pp. 163-169; Poole (1981), pp. 149-172, y Andrien (1984), pp. 1-20.

4 Gibson (1964), pp. 81-97, y Lohmann Villena (1957), pp. 3-30.

5 Varios estudios importantes, más recientes, de carácter regional, donde se trata el papel de los corregidores de indios y los sistemas tributario y laboral de la América Central y Perú en los siglos xvi y xVII, son los siguientes: MacLeod (1982), pp. 53-68; Spalding (1975), pp. 31-147; Spalding (1982); Stern (1982 a); Escobedo (1979), y Cole (1981).

- Fisher (1970), pp. 78-123.

${ }^{7}$ Las cifras de población de este estudio están tomadas de los decisivos estudios de- 
de este estudio es utilizar los datos del tributo indígena (impuesto por cabeza) y las cifras de población obtenidas de las cuentas de la tesorería del distrito de Lima, con el fin de: 1) reexaminar la extensión del fraude y la incompetencia; 2) determinar cuándo se generalizaron dichas prácticas, y 3) ofrecer algunas conclusiones sobre el efecto de estos abusos sobre las relaciones hispano-indígenas. El estudio se inicia en 1580, porque por entonces habían entrado ya en vigor las reformas administrativas del virrey Francisco de Toledo, y existen cifras de impuestos más fidedignas. Concluye en 1630, porque sobre esa fecha empiezan a ser escasas y poco fiables las cifras demográficas hasta finalizar el siglo, con la aparición del censo (numeración) del duque de la Palata en $1683^{8}$.

\section{Las reformas de Francisco de Toledo}

Desde el comienzo de su administración, Francisco de Toledo estaba decidido a extender el poder del Estado a expensas de la rebelde élite encomendera. En aras de este objetivo, el virrey otorgó a los corregidores de indios el papel central en la recaudación del tributo indígena. Los encomenderos habían disfrutado de este privilegio desde la conquista, pero sus excesos y la decidida voluntad de Toledo de lograr el control directo de los excedentes económicos locales indujeron al virrey a conceder este poder a los corregidores nombrados por la Corona 9. Tras una exhaustiva visita general del reino, Toledo empezó a poner en movimiento sus planes administrativos, con la orden de que toda la población indígena fuera congregada en grandes pueblos de estilo español denominados reducciones. A continuación , organizó dichas reducciones en 614 distritos administrativos, que llamó repartimientos, dirigidos por un jefe de clan indígena, un curaca. Los repartimientos fueron, a su vez, agrupados en 80 provincias o corregimientos, y cada uno de éstos quedó

mográficos de Noble David Cook, que utilizó como fuentes las listas tributarias de los corregidores de indios: Cook (1981), p. 88. Gran parte de los datos elementales empleados en el trabajo de Cook pueden encontrarse en Cook (1973), y Cook (1982), pp. 73-120.

- Cook (1982), p. 119. Los estudios recientes que tratan sobre los censos de población amerindia en el Alto Perú, en el siglo XviI, son los siguientes: Sánchez-Albornoz (1978); Sánchez-Albornoz (1982), pp. 11-19, y Evans (1981), pp. 25-44.

A partir de la conquista española, los miembros de la expedición de Pizarro repartieron los pueblos indígenas en concesiones de encomiendas, y adoptaron la costumbre inca de recaudar impuestos en mercancías y trabajo. La historia de la Península Ibérica proporciona también numerosos precedentes de recaudaciones de impuestos por cabeza. Romanos, visigodos y musulmanes cobraron este tipo de tributo en una forma u otra $y$, a partir del siglo XI, la Corona solía exigir un impuesto por cabeza, denominado pecho, para obtener rentas y afirmar la soberanía real. Escobzdo (1979), pp. 23, 25, 54-63, y Ballesteros y Beretta (1922-24), tomo II, p. 695. 
bajo la autoridad de un corregidor de indios ${ }^{10}$. El corregidor tenía competencia sobre la justicia, las relaciones comerciales entre españoles e indios y la recaudación de los tributos reales ${ }^{11}$. En suma, las reformas de Toledo consiguieron arrebatar a los encomenderos el dominio de las zonas rurales, entregándoselo a los representantes del Estado colonial.

Francisco de Toledo dedicó después su atención a racionalizar y controlar la extracción de los recursos económicos de las comunidades que poblaban las aldeas andinas, cosa que realizó mediante el establecimiento de unas tasas impositivas uniformes ${ }^{12}$. A diferencia de los anteriores intentos de imponer tasas, en 1548 y 1559 , las reformas administrativas del virrey hicieron imposible que los encomenderos pudieran sabotear este esfuerzo ${ }^{13}$. Se asignó una tasa a cada repartimiento del reino, basándose en la riqueza material de Ia región y en su población ${ }^{14}$. Aunque estas tasas se consideraron como exacción comunal, cada individuo era responsable del pago de una parte predeterminada de la cantidad fijada para cada repartimiento. De este modo, Francisco de Toledo seguía la tradición, tanto del precedente inca de determinar una cantidad a pagar comunalmente como del Derecho romano y del español, según los cuales semejantes exacciones debían aplicarse como impuesto personal por cabeza ${ }^{15}$. Todos los varones adultos entre las edades de dieciocho y cincuenta años pagaban el tributo, pero la proporción individual de la tasa comunal variaba según el status social del contribuyente. Los miembros de la ${ }^{10}$ López de Caravantes (1632), f. 182; Escobedo (1979), p. 56, y Lohmann Villen
(1957), p. 188.

11 Lohmann Villena (1957), pp. 204-230, 509-564.

12 Los objetivos de la visita general eran los siguientes: asegurarse de que se recaudaba todo el tributo siguiendo las reales órdenes; establecer unas tasas razonables recaudatentes en todas las provincias; acabar con la explotación de los indios por parte de corras encomenderos y caciques; fomentar el pago del tributo en metálico, y confeccionar un censo de la población indígena. Además, Francisco de Toledo ordenó a a confeccionar un del equipo que realizaba la visita que interrogaran a los indios que hubieran estado pre-
viamente bajo dominio inca sobre los pormenores viamente bajo dominio inca sobre los pormenores del sistema tributario inca. El virrey
ordenó también a su ayudante, Pedro Sarmiento de Gamboa, ción sobre los incas y escribiera una historia seria sobre los, que reuniera más informanecesitaba esta clase de información para levar a efecto sus mismos. Toledo pensaba que fiscal de Perú. Lohmann Villena (1957), p. 90; Toledo (1921)

${ }^{13}$ Escobedo (1979), pp. 34-50.

14 Escobedo (1979), p. 57.

is Según el jurista Juan de Solórzano y Pereyra, si se cobraba el tributo como una cantidad única a pagar por toda la comunidad, sería legal el mantener la tasa tributaria si la Corona consideraba el tributo como pago por cabeza y lo recaudab. Por otra parte, el Derecho español permitía que se rebajaran las tasas para compensar las rividualmente, población. En consecuencia, Francisco de Toledo decidió asignar unas las reducciones de cada repartimiento, pero hizo responsable a cada tributario del unas tasas tributarias a parte predeterminada de la tasa comunal. De esta forma, el impuesto el pago de una guía la tradición inca de asignar la contribución comunalmente. Sosto era equitativo y secap. XX, núms. 46-48, y cap. XIX, núm. 36; Lohmann Villeng (órzano (1972), libro II, 
estructura tribal de la comunidad (tributarios u originarios) pagaban una parte mayor de la tasa, mientras que a los miembros de la casta yanacona se les asignaba una parte menor ${ }^{16}$. Bajo el imperio inca, los yanaconas eran parias sociales que no pertenecían a un clan específico, y se dedicaban, por lo general, a labores serviles en los pueblos, como criados u obreros manuales. Dado que eran casi siempre los miembros más pobres de la comunidad, Toledo les impuso una carga tributaria menor ${ }^{17}$. Ahora bien, como promedio, cada tributario indio pagaba entre cinco y seis pesos anuales de impuestos, cantidad considerablemente mayor que las que se cobraban en México ${ }^{18}$.

El virrey Toledo estableció también una serie de normas para la recaudación y desembolso de las rentas tributarias. La ley original estipulaba que el tributo se recaudara en tres plazos anuales iguales (tercios), pero Toledo abandonó esta práctica a favor de una recaudación bianual ${ }^{19}$. El procedimiento legal exigía que el corregidor anunciara la tasa comunal un mes antes de las fechas de recaudación, que se habían fijado en los días de San Juan, en junio, y Navidad, en diciembre ${ }^{20}$. Para simplificar el sistema de recaudación, Toledo intentó fomentar el cobro de impuestos en metálico, en lugar de en especie ${ }^{23}$. Pero, al no ser ello posible, la Corona confió al corregidor la tarea de determinar el valor del tributo en especie, según el precio de mercado vigente de los productos. Al margen de que se cobrara en metálico o en género, los curacas del pueblo recaudaban el impuesto en los días fijados, y enviaban después el producto al pueblo principal del repartimiento, donde era entregado al corregidor y sus lugartenientes. El corregidor utilizaba la recaudación para pagar los salarios locales, a los párrocos, o sinodos, y demás gastos administrativos. Lo que restaba iba al encomendero o a la oficina del tesoro, o caja, más próxima. Según una autoridad coetánea, en 1632 la distribución de los 1.384.228 pesos recaudados en concepto de tributos en Perú fue la siguiente: 8.614 pesos $(0,6$ por 100) para la beneficencia local, 53.920 pesos ( 4 por 100) para salarios de caciques, 181.305 pesos ( 13 por 100) para los corregidores y sus lugartenientes, 280.840 pesos (20 por 100) para los sínodos y 859.540 pesos (62 por 100) para el tesoro o los encomenderos 22 . Para garantizar la limpieza de todo este proceso, la Corona exigía que se hallara presente el párroco.

Según el procedimiento establecido por Francisco de Toledo y la Corona,

16 Escobedo (1979), pp. 23-25.

17 Levillier (1938), 8, p. 253.

18 Escobedo (1979), p. 104.

19 Escobedo (1979), p. 104.

${ }^{20}$ Escobedo (1979), p. 104.

21 Escobedo (1979), pp. 119-126.

22 López de Caravantes (1632), f. 182; Lohmann Villena (1957), pp. 89-90. 
una vez que el dinero del tributo llegaba a la caja local, los funcionarios de la Corona registraban el producto en cuatro ramos distintos: tributos reales, tributos vacos, lanzas y, más tarde, tercias y encomiendas. Dichos funcionarios incluían los ingresos de los repartimientos que estaban bajo autoridad real directa en el ramo de tributos reales. La contribución de los pueblos donde había quedado vacante una encomienda se registraba como tributos vacos o vacantes de encomiendas. Pero los impuestos de determinadas encomiendas vacantes se destinaban para el pago de los salarios de la guardia virreinal (guarda de lanzas y arcabuces), y se incluían en el ramo de lanzas. La cantidad asignada originalmente a este fin, en 1554 , era de 114.500 pesos, pero hacia 1619 dicha suma había descendido a 66.354 pesos. Los guardias, cuyo cargo era en gran medida honorífico, aceptaron en 1619 cumplir con sus deberes más elementales sin paga, y estos fondos revertieron a la Corona ${ }^{23}$. La última clasificación tributaria, las tercias de encomiendas, entró en vigor mucho tiempo después de la muerte de Francisco de Toledo, en 1619. A partir de 1550, la Corona había exigido a los poseedores de tierras que pagaran un quinto de sus rentas a la Corona, pero esta normativa no había llegado a aplicarse nunca de modo efectivo ${ }^{24}$. En consecuencia, cuando empezaron a descender los ingresos tributarios en Perú durante el siglo xvir, la Corona ordenó a todos los encomenderos que pagaran una tercera parte de sus rentas a la caja del tesoro más próxima, donde se registraban como tercias de encomiendas ${ }^{25}$. No obstante estos diversos apartados de las cuentas reales, los cuatro ramos representaban un solo impuesto: el tributo indígena.

El virrey Toledo codificó, asimismo, la legislación existente, y emitió nuevas leyes u ordenanzas, en un intento de definir rígidamente los procedimientos para la administración del sistema tributario ${ }^{26}$. Los corregidores, por ejemplo, debían mantener un padrón minucioso de cada repartimiento, confeccionado con los registros parroquiales. Estos padrones constituían la base de las listas fiscales, o matrículas, del corregidor. La Corona exigía también que el corregidor actualizara las matrículas cada tres años, así como la tasa comunal, y entregara copias de ambas en la caja más próxima. Si se producía algún cambio de población dentro del período trienal, los miembros de la comunidad indígena tenían derecho a pedir un censo nuevo y una retasa (nueva tasación del tributo) ${ }^{27}$. Como medida adicional para evitar la malversación, la

${ }^{23}$ Escobedo (1979), pp. 149-151; Recopilación de leyes de los reynos de las Indias (Madrid, 1680, 1973) (en adelante, citado como Recopilación), libro II, título III,
ley XVII; Solórzano (1972), libro III, cap. XXXIII, núms. 2, 5. 24 Torres Saldamando (1967), p. 34. Escobedo (1979), 2, 5.

bro VI, cap. VII, núm. 1, y cap. XXVII, núms. 1-6; Zavala (1973), Solórzano (1972), li-

${ }_{25}$ Recopilación, libro VI, título VIII, leyes $38,39$.

${ }_{27}^{26}$ Las ordenanzas de Toledo pueden encontrarse en Levillier (1938). 
ley estipulaba que cada corregidor debía depositar una fianza en la caja local. Si se producía algún déficit en la recaudación tributaria, la fianza del corregidor podía quedar enajenada hasta que se hubiera restituido la cantidad ${ }^{28}$. La Corona instruyó, asimismo, a los corregidores para que llevaran cuentas detalladas de sus actividades financieras, que eran examinadas en la caja local y, a partir de 1607 , en el tribunal de cuentas de Lima ${ }^{29}$. Finalmente, cada corregidor estaba sujeto a una revisión judicial o residencia al dejar el cargo, ejecutada por su sucesor. Francisco de Toledo y sus superiores de Madrid esperaban que semejantes medidas garantizaran el funcionamiento justo y eficaz del sistema tributario del Perú, muy centralizado y bajo control estatal.

Pero, no obstante los esfuerzos del virrey Toledo y del Gobierno de Madrid para evitar abusos, una gran variedad de fuentes clericales y burocráticas de los siglos xvi y xvil atestiguan que la corrupción y la incompetencia habían empezado a socavar el sistema impuesto por Toledo poco tiempo después que éste abandonara Perú. La gran mayoría de las críticas estaban dirigidas contra los corregidores. Se decía que estos magistrados desatendían las leyes, abusaban de su autoridad y se enriquecían a costa de la Corona y de los indios. En efecto, un observador, Francisco Falcón, calculaba que los corregidores extorsionaban de tal modo a sus subordinados que no había indio en Perú que pudiera poseer ni tan siquiera cinco vacas u ovejas, a menos que se tratara de un curaca ${ }^{30}$. Otro coetáneo estimaba que un corregidor poco escrupuloso, y emprendedor, podía reunir hasta 30.000 pesos anuales, mientras que el salario legal del cargo oscilaba entre 800 y los 1.200 pesos ${ }^{31}$.

Son abundantes los testimonios del período que indican que los corregidores empleaban una gran variedad de métodos ingeniosos para circunvenir la ley y llenarse los bolsillos con fondos tributarios ilícitos. Era común que falsificaran censos y matrículas, para dar una cifra inferior de los tributarios de sus repartimientos, con objeto de apropiarse el dinero pagado por los que no quedaban legalmente incluidos en las matrículas. Otra táctica de este tipo era la de obligar a los indios a pagar impuestos por personas muertas o que habían abandonado el repartimiento, así como por ancianos y otras categorías legalmente exentas del tributo. En estos casos, las tasas que se aplicaban a las aldeas indígenas obedecían, al parecer, sólo al capricho del corregidor, en lugar de ser las tasas legales fijadas por el virrey Toledo. Más aún, algunos coetáneos llegaron a afirmar que había magistrados poco escrupulosos que adjudicaban un valor anormalmente bajo a los tributos recaudados en especie,

26 Lohmann Villena (1957), pp. 285-288, 290.

29 Recopilación, libro VIII, título IX, ley 17.

30 Falcón (1918), p. 143.

31 Vázquez (1842-95), p. 582. 
lo cual constituía un fraude, tanto para el tributario como para la Corona, pero permitía al corregidor obtener un pingüe beneficio cuando vendía los productos a su verdadero precio de mercado. Era también sabido que los corregidores retenían fondos tributarios pertenecientes a la Corona, con el fin de financiar sus propias empresas locales. Se decía que algunos magistrados habían, incluso, empleado mano de obra indígena sin pagarla, en provecho de sus operaciones. En 1580, por ejemplo, una visita al corregimiento de Cañete reveló que el magistrado estaba utilizando obreros indios sin sueldo del pueblo de Carabayllo para sembrar los trigales que él poseía en la provincia. Este abuso de la ley se produjo en el distrito de Lima, durante los últimos años del virreinato de Francisco de Toledo ${ }^{32}$.

Tan amplia evidencia de malversación no pasó inadvertida en Madrid, y en 1604 y 1626 los funcionarios de la Corona contemplaron seriamente la posibilidad de abolir el sistema de corregimientos en las Indias ${ }^{33}$. A pesar de que la Corona optara por no tomar una acción tan severa, hacia comienzos del siglo xvir acompañaban a todos los títulos oficiales del cargo una serie de instrucciones detalladas, donde se especificaba que los magistrados debían: pagar sus fianzas sin falta, recaudar solamente los impuestos legalmente exigidos, no tomar productos de los indios sin pagarlos, no tomar dinero prestado de las cajas de comunidad indígenas, mantener al día los padrones y matrículas y no permitir que se produjeran rezagos (deudas tributarias) ${ }^{34}$. Esta lista de actos prohibidos implica un evidente reconocimiento por parte de Madrid de que los abusos del sistema tributario perjudicaban al Estado colonial, representaban una pérdida de ingresos grande e inaceptable e imponían una pesada carga sobre la población indígena.

\section{Metodología para verificar el fraude y la incompetencia}

Las acusaciones de corrupción dirigidas contra los corregidores pueden verificarse comparando la relación estadística existente entre los recuentos de población indígena y las rentas del tributo depositadas en las reales cajas del virreinato. Si la administración del sistema tributario era justa y eficaz, debe existir una fuerte correlación estadística entre la población indígena de los diversos distritos y la cantidad de tributos enviada cada año por el corregidor de indios. Puesto que la ley exigía que las tasas a pagar se fundamentaran en

${ }^{32}$ Keith (1971), p. 441.

33 Yalí Román (1974), p. 26.

4 Gibson (1964), pp. 90-91; Archivo General de Indias (en adelante, citado AGI), Lima, 635, Título de Santiago de Pontejos, corregidor de Ica, Madrid, 17 enero 1669. 
el número de población amerindia de los repartimientos, los descensos o aumentos demográficos tendrían que haber producido un impacto directo sobre las rentas tributarias con el paso del tiempo. Efectivamente, la Corona emitió cédulas en 1546, 1551 y 1558, en las que se ordenaba que las tasas se ajustaran periódicamente para compensar cualquier alteración en la población indígena ${ }^{35}$. Si los corregidores de las provincias del Perú aplicaron dichas leyes de modo injusto y honrado, las cantidades de dinero procedentes del tributo registradas en las reales cajas tienen que exhibir una clara correlación matemática con las cifras de población indígena de Perú, desde 1580 a 1630 . Pero una correlación clara, sin embargo, no necesariamente demuestra de modo concluyente que la corrupción y la ineptitud no fueran habituales en este período. Los corregidores podían haber enviado fielmente la parte del tributo correspondiente a la Corona, y haber malversado total o parcialmente el resto del dinero recaudado. Un magistrado poco escrupuloso podía, por ejemplo, quedarse con dinero del encomendero, saquear las cajas de comunidad, dejar de pagar los salarios del clero, o incluso utilizar fondos reales para negocios ilícitos. En pocas palabras: dicha comparación entre cifras de población y rentas tributarias sólo nos descubrirá las formas flagrantes y verificables de corrupción e incompetencia administrativa en el nivel local. Por otra parte, si no existe una correlación alta entre estas dos variables, ello supondrá una fuerte evidencia a favor de los testimonios coetáneos que acusaban a los corregidores de malversación e ineptitud.

La falta de datos sobre las rentas tributarias para la mayor parte de las cajas, entre 1580 y 1630 , limita este estudio al examen del distrito de Lima ${ }^{36}$. Sólo existen registros fragmentarios para las restantes cajas, a excepción de la de Potosí, pero los trabajos demográficos realizados para el Alto Perú en este período son, por el momento, insuficientes, lo cual nos impide utilizar dicha caja para este estudio ${ }^{37}$. Además, la caja de Lima tenía jurisdicción sobre las ricas provincias de las costas y tierras altas centrales, por lo que disponía de una base geográfica y económica muy diversa. Aún más, debió haber sido una de las cajas de Perú más eficaz y honradamente administrada. El virrey y el tribunal de cuentas podían vigilar allí la entrada de fondos del tributo con más facilidad que en regiones remotas, como Huamanga y Cuzco, y a lo largo de este período fue raro que los inspectores reales descubrieran rezagos en la caja de Lima. En consecuencia, si hubo fraude o incompetencia en la jurisdicción de la caja de Lima, es también muy probable que se diera en las cajas más lejanas del interior.

${ }^{35}$ Recopilación, libro VI, título V, leyes $24,37,45,51$.

${ }^{36}$ Para una lista de los documentos de la tesorería existentes, correspondientes a las cajas del Virreinato del Perú entre 1580 y 1630, véase Te Paske y Klein (1982).

${ }^{37}$ Te Paske y Klein (1982), II, pp. 258-293. 
Según las cuentas de la caja de Lima, el área geográfica bajo su jurisdicción permaneció inalterable entre 1580 y $1630^{38}$. Durante este período, la caja tenía autoridad sobre los corregimientos de Cajatambo, Cañete, Canta, el Cercado de Lima, Chancay, Huarochirí, Ica, Jauja y Yauyos (véase mapa). Ello implicaba que los funcionarios del tesoro tenían la responsabilidad de inspeccionar los envíos de tributos de repartimientos muy dispersos, como eran Laspas, Orcos, Cajatambo, Ambar y Andax, en Cajatambo; Chilca y Mala, Coayllo y Colango, Lunaguaná, Guarco y Chincha, en Cañete; Hananpiscas, Urinpiscas, Atabillos, Guamantanga y Xecos y Canta, en Canta; Guancayo, Comas Caravaillo, Surco, Purucho, Lati, Chiquitanta, Maranga y Guatca, Magdalena, Luringancho, Pachacamác, Manchay, Guanchoguaylas y Cacahuasi, en el Cercado de Lima; Barranca, Cupi, Végueta, Huaura, Chacay, Cupilin Huaral, Aucayama y Checras, en Chancay; Chacalla, Mama y Huarochiri, en Huarochirí; Pisco y Cóndor, Umay, Manaica, Lurinica y Nasca, en Ica; Mitimas de Jauja, Mitimas Yauyos Mama, Mitimas Yungas, Mitimas Mango Laraos, Atún Jauja, Lurin Guanca y Hanan Guanca, en Jauja; y Mitimas Yauyos, Colpas Atunyauyos, Mitimas Huarochirí, Mitimas Chacllas, Mitimas Chocorbos, Mitimas Mamas, y Mango y Larao Aymara en Yauyos ${ }^{39}$.

Los innovadores estudios demográficos de Noble David Cook, para Perú, permiten realizar estimaciones de la población tributaria indígena perteneciente al distrito de la caja de Lima entre 1580 y 1630 (véase apéndice I). Estas cifras representan proyecciones cuantitativas, con frecuencia fundamentadas sobre datos resumidos en dicho período ${ }^{40}$. En consecuencia, podría cuestionarse el número exacto de tributarios enumerados en el apéndice I para cualquier año dado, pero las tendencias demográficas básicas que muestra son claras y precisas. Estas cifras de población, objeto del gráfico I, indican que la población tributaria indígena descendió acusadamente de 30.394 en 1580 a 14.690 en 1630 , un descenso superior al 50 por 100 . El efecto de las epidemias y la emigración en esta caída demográfica de Perú, estudiada por algunos demógrafos históricos como Cook, fue particularmente severo en el distrito de Lima.

El determinar la cantidad total de tributos recogidos en el distrito de la caja de Lima, a partir de las cuentas fiscales, planteaba una serie de problemas metodológicos muy serios. No figura en las cuentas una sola partida que incluya todas las rentas tributarias de la región. La mayor parte de los tributarios, por ejemplo, vivía en aldeas que quedaban bajo jurisdicción de una en-

3 AGI, Contaduría, 1693-1714, Cuentas de la Caja de Lima, Lima, 1580-1630.

39 AGI, Contaduría, 1693-1714, Cuentas de la Caja de Lima, Lima, 1580-1630.

to Cook (1973), pp. 352-353, 404-408, 413-414; Cook (1982), pp. 73-75, 115-120; Cook (1981), pp. 75-114. 


\section{GRAFICO I}

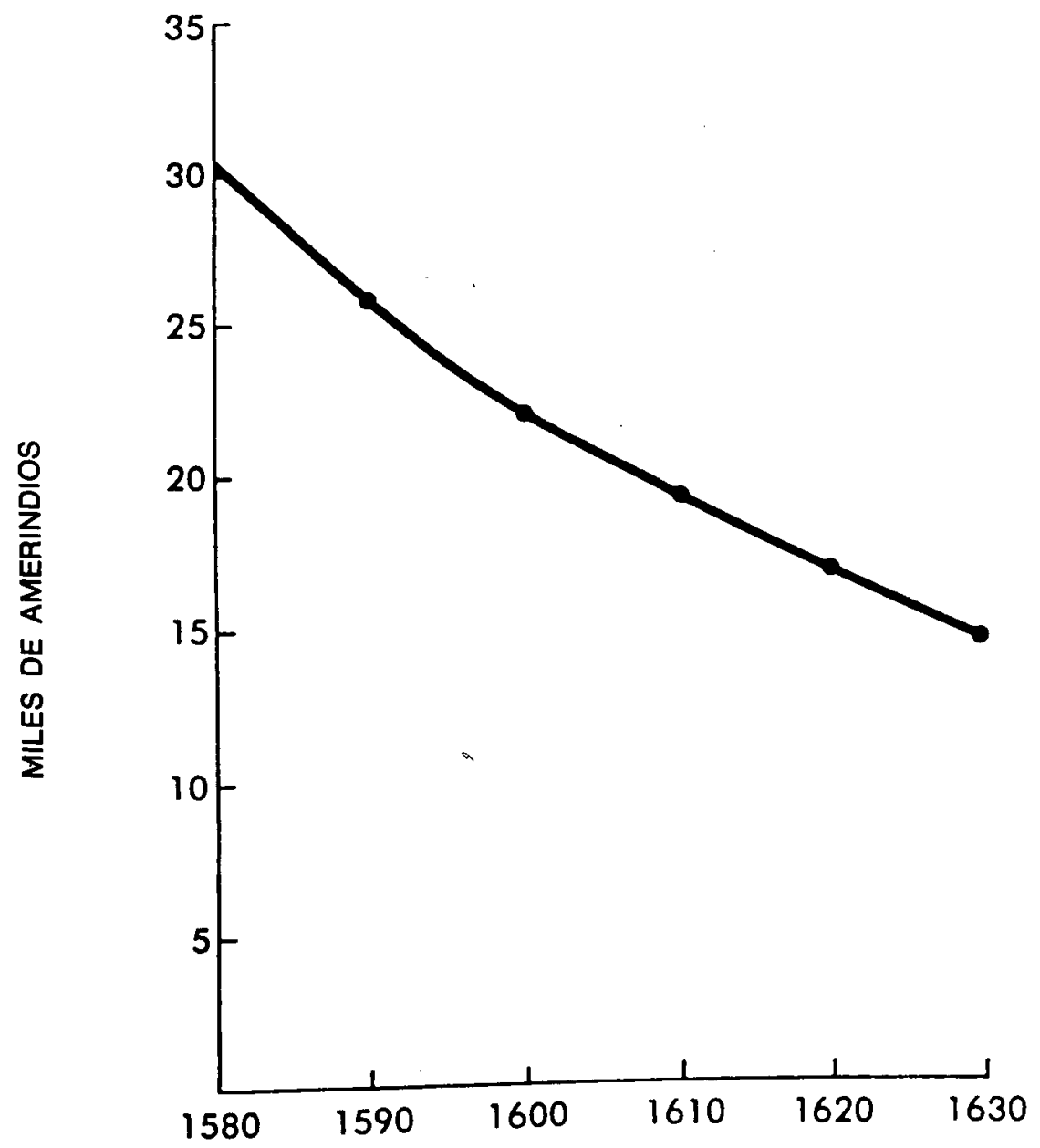

comienda. En efecto, un coetáneo, Antonio de León, calculaba que hacia 1631 las encomiendas del distrito de Lima producían más de 82.000 pesos anuales en tributos ${ }^{4}$. Dado que los corregidores enviaban cualquier beneficio producido por el tributo al encomendero en lugar de a la caja, este dinero no se

${ }^{41}$ Zavala (1973), p. 242. 
registraba en las cuentas de Lima. La única ocasión en que se registraba en las cuentas de la caja el dinero del tributo de las encomiendas era cuando éstas quedaban temporalmente vacantes. Pero incluso estas cifras son de difícil interpretación, porque los funcionarios del tesoro de Lima no distinguían, generalmente, con claridad, dentro del ramo de tributos vacos, entre el dinero del tributo procedente de los repartimientos bajo jurisdicción limeña y los fondos que venían de otros distritos de la tesorería ${ }^{42}$. Además, durante el período de 1580 a 1630 , la Corona adjudicó habitualmente las encomiendas vacantes a ciudadanos de mérito de España o de las Indias, o destinó sus rentas a la ayuda de instituciones públicas, tales como hospitales o la Universidad de San Marcos. Durante el reinado de Felipe III (1598-1612), por ejemplo, la Corona adjudicó más de 40 encomiendas en Perú, con rentas acumulables que superaban los 90.000 pesos ${ }^{43}$. Puesto que estas rentas de encomiendas vacantes volvían a asignarse rápidamente, en lugar de pasar al real tesoro, los registros de la recaudación del tributo anual procedente de estos repartimientos desaparecen de las cuentas de Lima. Después de 1619, ni siquiera las cantidades de dinero tributario incluidas en el ramo de tercias de encomiendas dan indicio de las rentas totales recaudadas en las encomiendas del distrito. En la práctica, los funcionarios del tesoro de Lima sólo recaudaban esta exacción en las encomiendas adjudicadas a partir de 1619, o en las que se habían transmitido como herencia ${ }^{44}$. Realmente, el único modo de rastrear el dinero del tributo recaudado en las encomiendas del distrito sería reconstruir estas cifras a partir de los libros de contabilidad de los corregidores o de los encomenderos. Dado que se han encontrado muy pocas de estas cuentas, es imposible determinar con precisión las grandes rentas anuales que producían las encomiendas del distrito de Lima.

Similares dificultades plantea el análisis de las cifras del ramo de lanzas. Estas rentas sólo se registraban esporádicamente en las cuentas de Lima, e incluso en los años en que se anotaba lo recibido, los funcionarios del tesoro no distinguían, por lo general, entre los fondos tributarios recaudados en Lima y los obtenidos en otros distritos. Como resultado, el ramo de lanzas no ofrece una relación anual de la cantidad de tributo reunido en aquellas encomiendas de Lima, que en 1554 se habían destinado al mantenimiento de la guardia virreinal ${ }^{45}$.

42 AGI, Contaduría, 1693-1714, Ramo de tributos vacos, Cuentas de la Caja de Lima, Lima, 1580-1630.

${ }^{43}$ AGI, Indiferente General, 754, Encomiendas, Madrid, 1598-1621; Lima, 1066, Reales cédulas de mercedes y pensiones, Madrid, 1606-1788; Escobedo (1979), p. 275, y Zavala (1973), pp. 238-242, 865, 899, 930.

${ }^{4}$ Escobedo (1979), pp. 181-184; Solórzano (1972), libro VI, cap. XXVII, núms. 1-6.

${ }^{45}$ AGI, Contaduría, 1693-1714, Ramo de tributos reales, Cuentas de la Caja de Lima. Lima, $1580-1630$. 
La única partida de las cuentas que representa, en efecto, remesas anuales de rentas tributarias procedentes de los corregimientos del distrito es la de tributos reales. Pese a que los fondos producidos por este ramo constituyen sólo una fracción del total de las rentas tributarias recaudadas en el distrito, la ley exigía que los corregidores enviaran estos ingresos a la caja todos los años, junto a las cuentas fiscales exactas. Estos fondos y las cuentas que los acompañaban eran revisados en la caja, y después en el tribunal de cuentas de Lima ${ }^{46}$. Además, puesto que el número de repartimientos incluidos en Lima en el ramo de tributos reales permaneció constante entre 1580 y 1630 , sólo los posibles cambios en la población indígena del distrito podrían haber incidido sobre la cantidad anual de dinero depositada en la caja, procedente de este ramo ${ }^{47}$. Por consiguiente, los tributos reales constituyen la única partida de las cuentas de Lima cuyo uso puede ser significativo en cualquier correlación estadística con las cifras de población indígena del distrito de Lima en los años 1580-1630.

Aún quedaba un problema a la hora de analizar las cifras anotadas en las cuentas de Lima correspondientes a los tributos reales: las entradas se registraban en tres monedas distintas: pesos ensayados, pesos de a ocho y reales. A pesar de que el valor de estas monedas de plata sufrió, sin duda, alguna variación durante el período, en Lima un peso de a ocho valía, por lo general, ocho reales, y los pesos ensayados doce reales y medio ${ }^{48}$. Para fines de la comparación, todas las cantidades se pasaron a pesos de a ocho, la moneda más utilizada en el virreinato durante el período que nos ocupa. Los resultados, que aparecen en el apéndice II, están representados gráficamente en el gráfico II.

Pese al continuo descenso de la población amerindia del distrito de la caja de Lima, las cifras del gráfico II indican que este desastre demográfico no se reflejó en los ingresos de la caja procedente del tributo. De haber funcionado eficazmente el sistema de Francisco de Toledo, la sostenida decadencia de la población tributaria tendría que haber producido retasas, un descenso de los tipos fiscales y una reducción en las remesas de rentas de los corregidores. Por el contrario, las cantidades registradas en el ramo de tributos reales fluctuaron desde los máximos de 1591, 1593, 1595, 1624 y 1627 hasta los períodos de descenso de 1590, 1597 y de 1608 a 1617 . Dichas fluctuaciones, que oscilaron entre los 3.522 pesos de 1590 y los 51.542 de sólo cinco años después, demuestran que los corregidores mandaban el dinero del tributo a Lima

46 Escobedo (1979), pp. 137-147.

47 AGI, Contaduría, 1693-1714, Ramo de tributos reales, Cuentas de la Caja de Lima, Lima, 1580-1630.

4 AGI, Contaduría, 1693-1714, Ramo de tributos reales, Cuentas de la Caja de Lima, Lima, 1580-1630. 


\section{GRAFICO II}

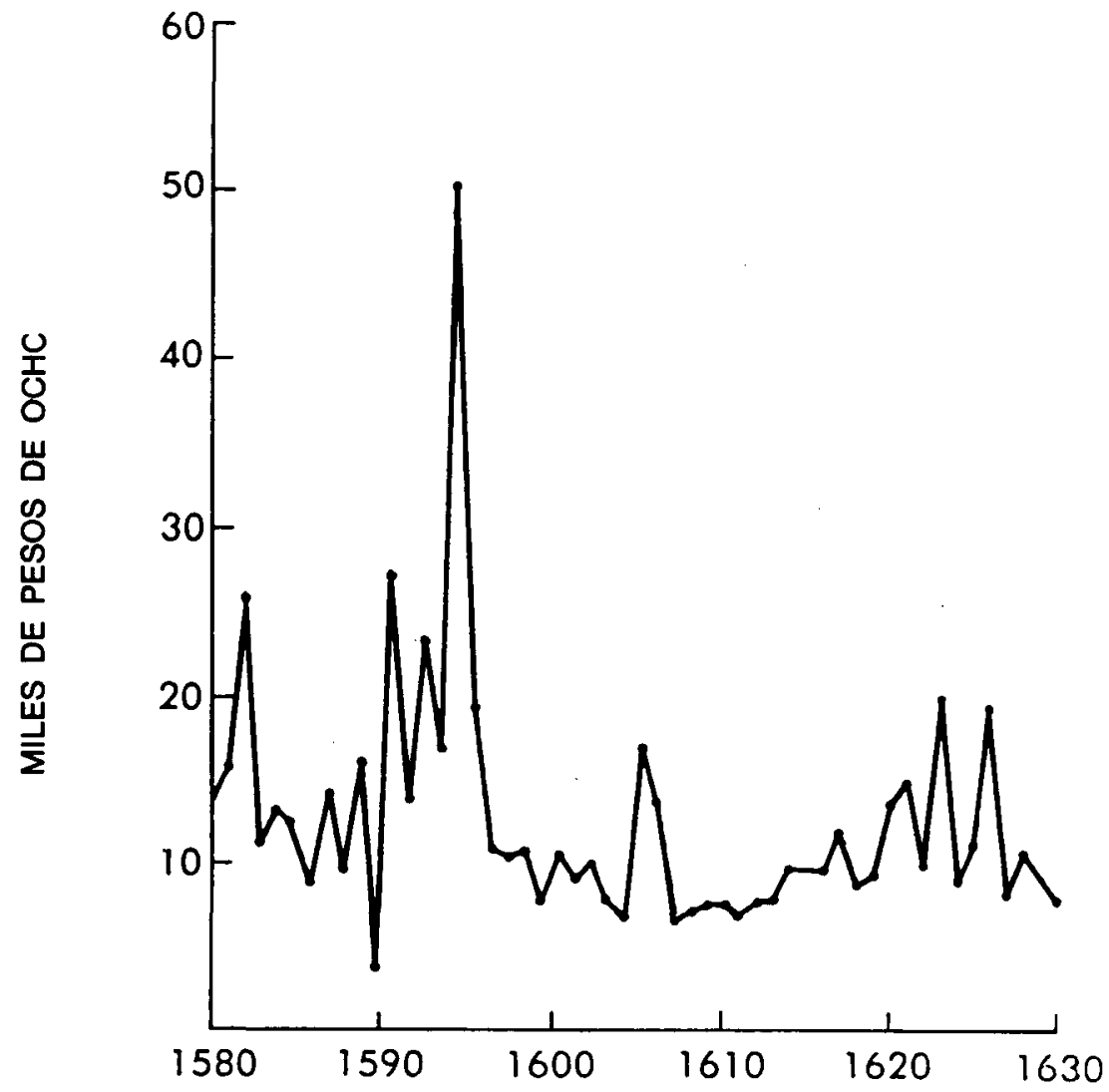

sobre una base irregular, no obstante las prohibiciones legales en sentido contrario. De hecho, las cantidades anuales fluctuaban tan acusadamente que no pueden haber correspondido a las cifras que los funcionarios del tesoro esperaban a tenor de sus matrículas. Estas conclusiones, algo impresionistas, quedaron confirmadas estadísticamente estableciendo una correlación entre las cifras de población amerindia y las rentas producidas por el tributo del distrito estudiado durante el período 1580-1630. El resultado fue un insignificante coeficiente de correlación de $0,2656^{49}$. Ello confirmaba que el dinero del tri-

- Se considera significativo, por lo general, un coeficiente de correlación del 0,5 o superior. Las cifras de población y de tributos as codificaron utilizando el paquete SPSSX. 
buto era, en gran medida, indiferente a los cambios en el número de indios contribuyentes. Efectivamente, las rentas fiscales empezaron a fluctuar de modo prácticamente independiente del número de tributarios a partir de la década de 1590, tan sólo diez años después que hubieran entrado en vigor las reformas del virrey Toledo. Es evidente que los esfuerzos de Francisco de Toledo para obligar a los corregidores a cumplir la ley empezaron a fracasar en Lima incluso antes del siglo Xviı, siendo Lima la caja más estrictamente regulada del virreinato de Perú.

La general corrupción e incompetencia de los corregidores es la explicación más plausible de esa ausencia de una correlación significativa entre los ingresos del tributo y el número de tributarios indígenas. Las fluctuaciones de estas rentas entre 1580 y 1630 eran excesivamente pronunciadas y frecuentes para que puedan explicarse por medio de retasas temporales, que compensaran el efecto de ciertos desastres naturales, como terremotos o inundaciones. Además, no se incluyeron nuevos repartimientos en el distrito de Lima, ni se incorporaron al ramo de tributos reales ${ }^{50}$. La subida transitoria de las rentas del tributo en 1624 y 1627, por ejemplo, fue simplemente resultado de una remesa más cuantiosa de fondos por parte de los corregidores de la capital. Semejante irregularidad en las cantidades enviadas por los corregidores era, por lo demás, corriente en el distrito de Lima. En 1610, por ejemplo, el corregidor de Chancay sólo envió 37 pesos en tributos reales del repartimiento de Aucayama, pero, diez años después, su sucesor logró mandar a Lima 1.200 pesos procedentes de la misma región ${ }^{51}$. Algunos repartimientos, como Mangos y Laraos, en Jaujà, pasaron incluso varios años sin mandar un solo real por tributos a la caja de Lima ${ }^{52}$. Los funcionarios del tesoro afincados en Lima, por su parte, no podían contener de modo consistente y eficaz la mala administración entre los corregidores, que quedaban nominalmente bajo su jurisdicción. El sistema de tasas y procedimientos administrativos, tan cuidadosamente ideado por Francisco de Toledo, estaba en ruinas a comienzos del siglo xvir.

Cada año se trató como un caso aparte, y las variables fueron: año, la cantidad de tributos reales en pesos de a ocho y el recuento de población de cada año. Para la correlación utilicé el subprograma Multiple Regression. El $R^{2}$ fue de 0,07 .

a tributos reales a partir de 1619 fue resultado de la incorporación de las rentas anteriormente designadas como lanzas al ramo de tributos reales. Una lectura atenta del ramo de tributos reales correspondiente a Lima demuestra, in embargo, que no fue así. De hecho, los funcionarios del Tesoro de Lima mantuvieron (1979), pp. 275-276, y AGI, Contaduría, 1693-1714, Ramos de tributos reales y lanzas, Cuentas de la Caja de Lima, Lima, 1580-1630.

AGI Contaduría, 1705A, Ramo de tributos reales, Cuentas de la Caja de Lima, Lima, 1610; 1708, Ramo de tributos reales, Cuentas de la Caja de Lima, 1620.

52 AGI, Contaduría, 1705B-1708, Ramo de tributos reales, Cuentas de la Caja de Lima, 1610-1620. 
Las implicaciones de esta quiebra administrativa del Estado colonial en el nivel local son claras. Al decaer la población indígena, aumentó la carga fiscal de los tributarios que quedaban en los repartimientos. En 1624, por ejemplo, los corregidores del distrito de Lima se las compusieron para enviar 20.133 pesos en tributos reales, uno de los totales anuales más elevados del período 1580-1630 (véase apéndice II). Los corregidores enviaron esta gran cantidad, pese a que la población tributaria del distrito se había reducido casi en un 50 por 100 (véase apéndice I). Hacia el siglo xviI se hizo aún más gravosa la contribución impuesta por la Corona sobre los tributarios amerindios, y se intensificó la opresión de los corruptos corregidores de indios.

Una abundante evidencia producida por las visitas indica que la corrupción de los corregidores y la pérdida de rentas tributarias estaban aún más generalizadas en las provincias alejadas de la capital virreinal. Según un miembro del tribunal de cuentas de Lima, Francisco López de Caravantes, en 1630 las deudas o rezagos del tributo habían alcanzado los 1.654 .057 pesos en el virreinato ${ }^{53}$. Como demuestra el cuadro I, las ricas provincias de las tierras altas de Potosí, Cuzco y La Paz eran las que habían acumulado los mayores rezagos. Una residencia al corregidor de Chucuito, Bartolomé de Osnayo y Velasco, halló, cuando dejó el cargo, que este magistrado debía 40.000 pesos

\section{CUADRO I}

Tributos y rezagos registrados en el virreinato del Perú por el tribunal de cuentas en 1630

\begin{tabular}{|c|c|c|}
\hline Regiones & $\begin{array}{l}\text { Tributo recaudado. } \\
\text { (pesos ensayados) }\end{array}$ & $\begin{array}{c}\text { Rezagos } \\
\text { (pesos ensayados) }\end{array}$ \\
\hline 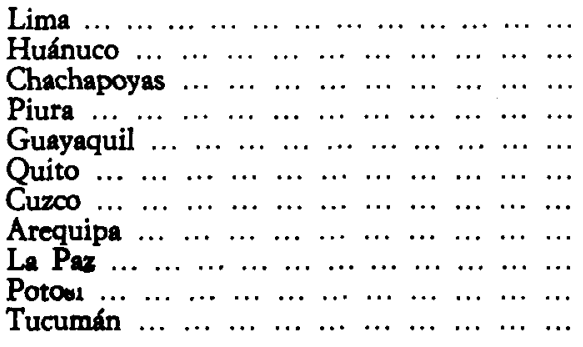 & $\begin{array}{r}6.359 \\
2.148 \\
60 \\
1.628 \\
50 \\
7.132 \\
33.851 \\
19.496 \\
16.330 \\
74.092 \\
1.280\end{array}$ & $\begin{array}{r}42.000 \\
399.588 \\
26.401 \\
180.785 \\
1.005 .282\end{array}$ \\
\hline 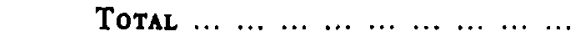 & 162.430 & 1.654 .057 \\
\hline
\end{tabular}

s3 López de Caravantes (1632), f. 182. 


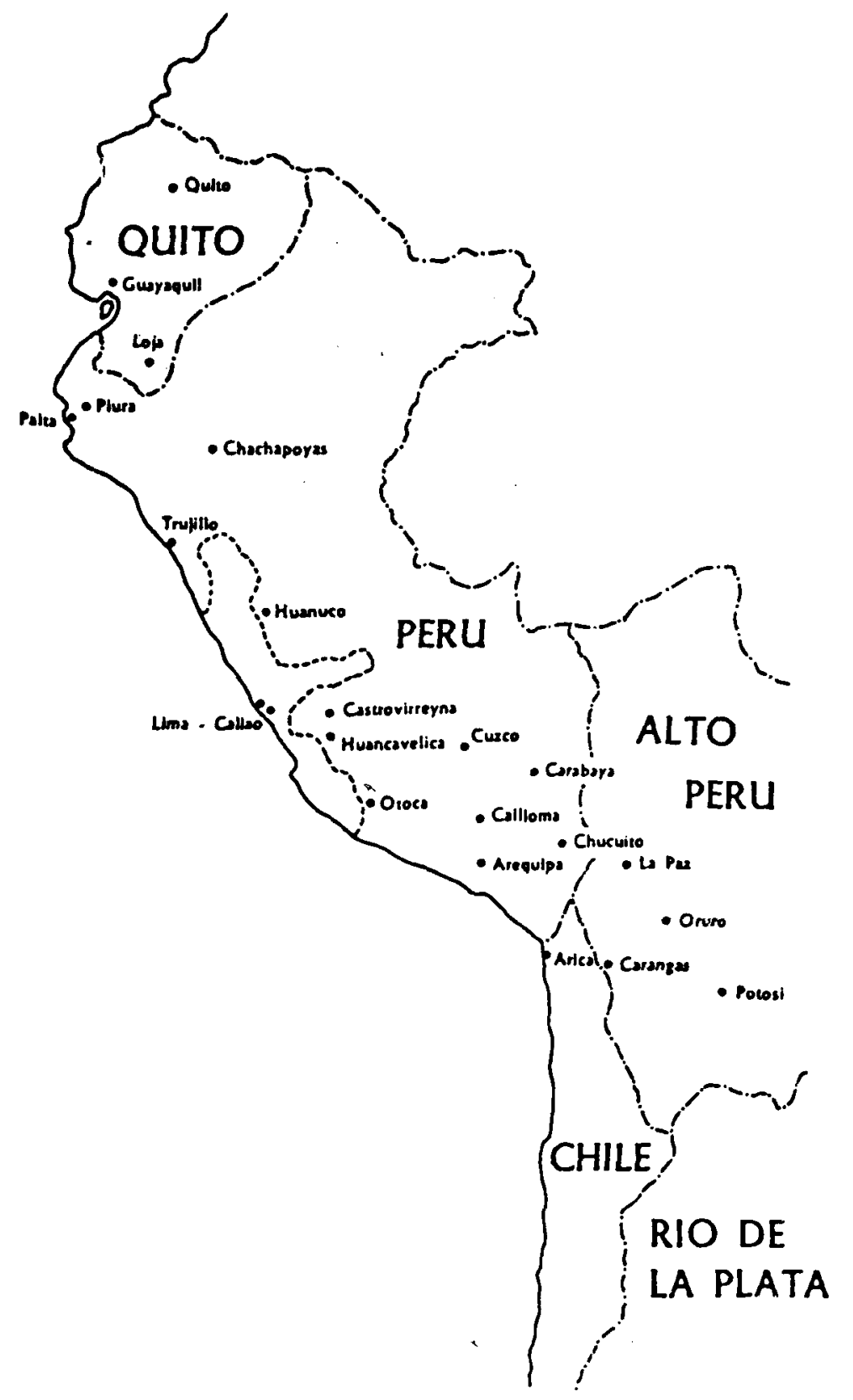


a la Corona en rezagos ${ }^{54}$. Más aún, las cifras de López de Caravantes sólo registraban las formas más flagrantes y más verificables del fraude de los corregimientos. Los abusos relativamente menores del distrito de Lima ni siquiera fueron revelados por López de Caravantes y el tribunal. Incluso cuando las autoridades de Lima descubrían, en efecto, evidencia de rezagos, según López de Caravantes, era infrecuente que se recuperara el dinero endeudado. En el momento de realizar la investigación, los rezagos tenían una antigüedad de decenas de años, y a menudo los responsables habían muerto o abandonado la región ${ }^{54}$. Con el tiempo, todos estos problemas se agravaron. En 1663, por ejemplo, una visita a los corregimientos peruanos proporcionó evidencia escandalosa de las mencionadas corrupción e incompetencia, al descubrir los investigadores que se habian acumulado 2.449 .286 pesos en deudas desde principio del siglo ${ }^{56}$. Era evidente que habían fracasado los esfuerzos de los virreyes y de Madrid por hacer cumplir las normas tributarias impuestas por Toledo.

\section{La decadencia del sistema de Francisco de Toledo}

Una de las principales causas de la proliferación de abusos en los corregimientos era el modo en que los intereses partidistas minaban las instituciones reguladoras del Estado, es decir, visitas, residencias, retasas y el sistema de reducciones de Francisco de Toledo. Mientras la Corona o las autoridades de Lima intentaban aprovechar las existencias de productos y mercancías locales, las élites regionales conseguían con frecuencia bloquear de modo efectivo la salida de esta riqueza económica. Los hacendados, los propietarios de talleres textiles (obrajeros), los corregidores $\mathrm{y}$, en algunos casos, incluso los curacas, podían conspirar para hacerse con el control de todo excedente económico, en lugar de enviarlo obedientemente a Lima. La configuración exacta de estos forcejeos sectarios variaba constantemente, dependiendo de los recursos que estuvieran en juego, pero todo ello contribuía a erosionar la eficacia de las instituciones establecidas por la Corona para explotar y controlar el tributo y el trabajo de los indios ${ }^{57}$.

Un síntoma importante de esta decadencia institucional era la progresiva laxitud del Gobierno de Madrid a la hora de supervisar la designación de corregidores en Perú. Desde fines del siglo xvi, la Corona empezó a permitir a las autoridades virreinales un control considerable sobre el nombramiento

* AGI, Lima, 39, Marqués de Guadalcázar a la Corona, Lima, 28 abril 1623, f. 241.

${ }^{33}$ López de Caravantes (1623), f. 182.

56 AGI, Lima, 280, Nicolás Polanco de Santillana a la Corona, Lima, 31 julio 1663.

57 Para un excelente análisis de este proceso en Huamanga, véase Stern (1982 b), pp. 289-320. 
de estos poderosos magistrados. En algunos casos, el virrey empleaba su autoridad para asegurarse de que cubrieran estos importantes puestos amigos o criados, mientras que, en otros, los intereses locales cabildeaban en el palacio virreinal hasta conseguir los puestos para sus propios candidatos. En efecto, los críticos del sistema protestaban que los nombramientos de todos los corregimientos peruanos, a excepción de Trujillo, Arequipa, Huamanga, Cuzco, Chacuito, La Plata y $\mathrm{La} \mathrm{Paz}$, estaban en 1588 dominados por el virrey y las élites locales ${ }^{58}$. Incluso circulaban rumores de que ciertos virreyes vendían los cargos abiertamente, lo cual proporcionaba a la élite local adinerada mayores oportunidades para hacerse con las magistraturas ${ }^{59}$. Pero, aun en el caso de que no se vendiera el corregimiento, en Perú se criticaba el hecho de que los designados para los cargos fueran con frecuencia magistrados absentistas, que preferían residir cómodamente en Lima, mientras las élites locales les compraban el derecho a asumir sus obligaciones en las provincias ${ }^{60}$. Si no dedicaba mayor atención a la cuestión de los nombramientos de corregidores, mal podía la Corona aspirar a controlar su conducta. Muchos corregidores y sus aliados consideraban, sencillamente, el cargo como una sinecura personal a emplear en provecho propio, particularmente si la cantidad que habían entregado a cambio del puesto excedía del salario legal.

Incluso los esfuerzos por estrechar la vigilancia de los corregidores, como era la fianza, podían convertirse en beneficio para los funcionarios deshonestos y sus compinches locales. La finalidad de la fianza era desalentar los rezagos y otras formas de mala administración, pero la realidad es que, generalmente, contribuyó a hacer más sólidos lòs lazos que unían a los corregidores con los comerciantes prominentes y los hacendados. Dado que con frecuencia la fianza superaba los medios del corregidor, éste solia buscar otras personas que pudieran garantizarla. En alguna ocasión era un pariente de España el que cumplía esta función, pero era más frecuente que algún ciudadano de las Indias le ayudara a depositar la cantidad. Después de todo, el corregidor podía utilizar su autoridad para proporcionar trabajadores temporeros a los propietarios de haciendas, o para favorecer a alguna casa comercial de Lima o de la capital provincial, deseosa de comerciar con la población indígena bajo jurisdicción del magistrado. Aunque el depósito de la fianza no necesariamente vinculaba al corregidor a los intereses de sus fiadores, sí suministraba una evidente oportunidad para que el magistrado deshonesto pudiera abusar de su poder y llenarse los bolsillos.

so Moreno Cebrián (1977), p. 30.

59 Yalí Román (1974), pp. 26-29; Tomás y Valiente (1972), pp. 85-86, 113.

El puesto de corregidor de indios no se vendió realmente hasta 1678. Lohmann Villena (1957), p. 125; Moreno Cebrián (1977), p. 83. 
Otra institución pensada para contener la corrupción, la visita, era con frecuencia igualmente ineficaz. En 1619, por ejemplo, el príncipe de Esquilache, virrey de Perú de 1615 a 1621, envió a una serie de visitadores para cobrar rezagos y castigar a posibles transgresores ${ }^{61}$. Aunque con estas visitas quedaron al descubierto ciertos abusos y se procesó a los culpables, su efecto fue escasamente perdurable. Una vez se hubieron marchado los jueces, la vida volvió a la normalidad, continuó la corrupción y se acumularon los rezagos. Además, estas inspecciones podían resultar costosas y perjudiciales para la administración local, pues los funcionarios descuidaban sus obligaciones con objeto de proporcionar a los visitadores los papeles que solicitaban. Muchas visitas producían también gran malestar a causa de las tensiones y los conflictos jurisdiccionales que surgían entre los investigadores y los funcionarios de la localidad. Otro problema era el de la fiabilidad de los testigos. El poderoso corregidor y sus secuaces podían intimidar o coaccionar a los testigos para que cambiaran su testimonio. $\mathrm{Y}$ las vendettas políticas de carácter local también contribuian a socavar la investigación. Incluso los prejuicios del juez podían adulterar el resultado del procedimiento. En suma, la visita resultaba a menudo un medio engorroso e ineficaz para contener la corrupción.

Aunque menos costosa y menos perturbadora que la visita, la residencia también sufría los efectos de los mismos prejuicios partidistas, testigos poco fiables y funcionarios locales reacios a cooperar. Pero la debilidad más evidente resultó ser la insistencia de la Corona en que fuera el sucesor del corregidor quien dirigiera la investigación. Con enorme frecuencia, el corregidor entrante tenía interés en ocultar aquellos abusos que él pretendía continuar una vez en el cargo. En consecuencia, las empresas comerciales ilícitas creadas con dinero del tributo, la contratación ilegal de obreros amerindios y los sobornos se repetían con los sucesivos corregidores. En 1617 y 1620, el réformista príncipe de Esquilache intentó cincunvenir las debilidades procesales de la residencia. Este virrey ordenó a los corregidores que enviaran tanto las cuentas fiscales como todos los fondos tributarios pertenecientes a la Corona a la caja del tesoro más próxima, antes de abandonar el cargo. La residencia no podía ni siquiera iniciarse hasta que los funcionarios del tesoro hubieran concluido con su inspección, y enviado el dinero de la Corona a Lima. El funcionario acusado de delinquir tenía que pagar los costes de la residencia y restituir todos los rezagos. Además, perdía el derecho a toda posibilidad de otro puesto burocrático, y quedaba sujeto a una pena máxima de seis años de exilio en Chile, entonces asolado por la guerra ${ }^{62}$.

Otra garantía institucional, que con frecuencia era anulada por el forcejeo

"L Lohmann Villena (1957), p. 283.

${ }^{62}$ Lohmann Villena (1957), p. 283; Escobedo (1979), pp. 114-115. 
político entre los intereses regionales y los supralocales, era la retasa. Para el corregidor y sus amigos, todo esfuerzo en pro de una revisión del censo y las matrículas representaba una amenaza a su dominio sobre los recursos locales. Así era, pues estos magistrados solían sacar provecho de la reducción del número de tributarios, arrancando dinero a los indios legalmente exentos de este impuesto y reteniendo asignaciones de la mita. Por su parte, los tributarios solicitaban continuamente las retasas con el fin de aligerar la carga que representaba esta clase de corrupción, explotación y engaño ${ }^{63}$. Pero sus esfuerzos pocas veces daban resultado. A menos que hubiera en Lima un virrey compasivo o entregado al cargo, como el marqués de Cañete (1590-1596) o Luis de Velasco (1596-1604), las peticiones de retasas quedaban generalmente desatendidas. Tras las retasas que siguieron a las graves epidemias de los años 1590, por ejemplo, el corregimiento de Yauyos sólo recibió dos retasas entre 1600 y 1662 , pese a las continuas pérdidas de población ${ }^{64}$. Aunque cada una de estas retasas redujo las tasas tributarias con respecto a los niveles impuestos por Toledo, eran excesivamente infrecuentes para hacer justo el sistema tributario y aligerar la carga fiscal de Yauyos.

La general decadencia del sistema de reducciones obstaculizó aún más la capacidad de los funcionarios de la Corona para dirigir y controlar el sistema tributario. Junto a las devastaciones generadas por las epidemias, las prácticas corruptas de los corregidores perjudicaban las finanzas del pueblo y animaban a los indios a huir de las reducciones establecidas por Francisco de Toledo ${ }^{65}$. Una vez lejos, los antiguos tributarios podían exigir legalmente el status de forastero, lo cual les proporcionaba una tasa impositiva más reducida y exención de la temida mita ${ }^{66}$. Algunos indios, incluso, procuraban la protección de hacendados, mineros o propietarios de obrajes, trabajando como obreros a sueldo en estas empresas dirigidas por españoles. Como escribiera el virrey Luis de Velasco en 1604: «con objeto de escapar del trabajo y las vejaciones que sufren en los pueblos, se marchan y huyen a esconderse en haciendas, en zonas montañosas o de matorral, y en cañadas, lo cual ha resultado en la desolación de las reducciones» ${ }^{67}$. Este aumento de población forastera era particularmente manifiesto en los repartimientos sujetos a la mita de Potosí. En efecto, en 1633, el visitador general de Perú, Juan de Carvajal e Sandi, calculaba que las enfermedades y las huidas eran causa de la pérdida de más

${ }^{63}$ Stern (1982 b), pp. 298-305.

* AGI, Contaduría, 1705A, 1748, Ramo de tributos reales, Cuentas de la Caja de Lima, 1610, 1622; Cook (1982), pp. 116-118.

${ }^{65}$ Escobedo (1979), p. 78.

*o Escobedo (1979), pp. 78-90.

${ }^{6}$ Santillán (1965), 2, pp. 319-320. 
de 3.100 tributarios de las 16 provincias que debían abastecer la mita de Potosí ${ }^{68}$.

El creciente número de forasteros creó cierta alarma en Lima a comienzos del siglo xvir. En 1616, el príncipe de Esquilache ordenó a los corregidores del virreinato que obligaran a todos los forasteros a regresar a las reducciones, con objeto de facilitar la recaudación del tributo ${ }^{69}$. A fin de cuentas, el incremento de forasteros - que pagaban una contribución ligera- no sólo reducía las rentas tributarias, sino que dificultaba la tarea de mantener censos y matrículas exactos. La Corona emitió una orden similar en una cédula del 9 de abril de 1628, y algunas autoridades de Lima, llegadas a la desesperación, incluso intentaron forzar a los corregidores a recaudar las tasas máximas entre los forasteros. Pero estos edictos no llegaron a imponerse de modo efectivo, y los indios continuaron abandonando las reducciones en cantidades similares ${ }^{70}$.

Otro factor que contribuyó a minar el sistema de Francisco de Toledo y su control sobre los impuestos locales fue la gradual integración entre las economías española e indígena a comienzos del siglo xvir. Este proceso fue parcialmente generado por la política fiscal y laboral establecida por el propio Francisco de Toledo. El forzar a los indios a sustituir el tributo en especie por pagos en metálico, por ejemplo, les indujo a vender sus productos y su trabajo a los europeos, con el fin de obtener el dinero que precisaban para pagar sus tasas. Asimismo, las obligaciones de la mita, impuestas por los corregidores, impulsaron a los obreros a emigrar a centros españoles para emplearse en las minas, obrajes y obras públicas, lo cual les llevó también a participar como consumidores y productores en la economía de mercado ${ }^{71}$. No es sorprendente, pues, que cuando los abusos de los corregidores se hicieran intolerables en los repartimientos aumentara la cantidad de amerindios que adoptaban un nuevo status, como empleados en las haciendas españolas, obreros independientes a sueldo o artesanos y criados urbanos ${ }^{2}$. En 1616, por ejemplo, el obispo de Huamanga escribía que se habían establecido en su distrito numerosos forasteros para trabajar en las minas y las haciendas rurales. El obispo observaba que estos forastetos eran, por lo general, aldeanos pobres que escapaban de sus obligaciones fiscales y de la mita en busca de un empleo en la economía española ${ }^{73}$.

Esta mayor circulación de mercancías y personas en la economía de mer-

6s Sánchez-Albornoz (1978), p. 70.

Escobedo (1979), pp. 86-87.

${ }^{70}$ Escobedo (1979), pp. 86-87.

1 Andrien (1985), pp. 11-41.

12 Cook (1981), pp. 87-88.

3 AGI, Lima, 37, Marqués de Montesclaros a la Corona, Lima, 7 diciembre 1615. 
cado virreinal era también fomentada por los empresarios españoles, deseosos de dominar la mano de obra, la tierra y otros recursos económicos que los forasteros podían proporcionarles. En el distrito de Lima, por ejemplo, los datos del censo correspondientes a Huacho y Végueta, en el valle del Chancay, indican que los hacendados españoles se beneficiaban de la mano de obra de los indios, que recorrían grandes distancias para abastecer la demanda regional de trabajo en las haciendas de trigo ${ }^{74}$. Pero al aumentar el número de amerindios que abandonaban los repartimientos y entraban en la economía de mercado, el sistema de tasas y reducciones cayó en el caos.

\section{Conclusión}

El resurgir de la autoridad central bajo Francisco de Toledo resultó no ser más que un fenómeno transitorio en el virreinato del Perú. Aparte de algún período breve tras una visita o una residencia, en el que las autoridades de Lima imponían una observación de la ley más estricta, los corregidores ejercían prácticamente un poder local independiente. Los negocios ilícitos, el soborno y la extorsión proliferaron, pues los corregidores utilizaron su autoridad judicial y administrativa de forma no menos tiránica que los encomenderos para extraer provecho de la población indígena a su cargo. Las garantías institucionales en el caso de los nombramientos burocráticos, o los procedimientos judiciales, raramente demostraron ser impedimentos serios; estos magistrados, sencillamente, hacían caso omiso de las leyes, y amasaron considerables fortunas mediante sus operaciones ilegales. En realidad, la erosión de la base fiscal del Estado virreinal, que se haría tan patente hacia 1650 , se había iniciado ya en los corregimientos rurales del distrito de Lima a fines del siglo XVI ${ }^{75}$.

La erosión del poder del Estado en los corregimientos peruanos entre 1580 y 1630 era prácticamente inevitable. Cuando Francisco de Toledo llegó a Perú, en 1569 , se le había confiado el cometido de gobernar un reino quebrantado por una guerra civil entre conquistadores. Ante la amenaza de un nuevo estallido de agitación civil y el peligro constante de un levantamiento indígena, dirigido por el inca Tupac-Amaru, en Vilcabamba, la burocracia colonial y los colonizadores españoles no podían menos que mostrarse receptivos a los planes de este reformador para unificar el reino bajo un Gobierno central

${ }^{74}$ Cook (1981), pp. 146-150.

${ }^{75}$ Para una descripción del papel que desempeñaban la corrupción y la incompetencia burocráticas en la decadencia del Estado virreinal hacia 1650, véase Andrien (1984), pp. 1-20. 
fuerte. Como buen representante de la Corona, Toledo aprovechó su sólida posición política para afirmar el poder del Estado mediante la reestructuración de los lazos económicos y políticos entre españoles e indios y la canalización de excedentes económicos hacia España. El funcionario clave del aparato estatal de Francisco de Toledo en las provincias rurales del Perú era el corregidor de indios, a quien se le otorgó autoridad para organizar y controlar el trabajo y la riqueza de las comunidades andinas. Desde un principio, sin embargo, estos magistrados abusaron de su poder, aliados con frecuencia a una serie de redes locales, regionales y suprarregionales de élites españolas. Además, al agravarse la explotación por parte de los corregidores y sus aliados, muchos indios escaparon de las reducciones creadas por Toledo para buscar trabajo en los pueblos, haciendas o minas españolas. El número de indios que efectuó la transición de las reducciones a los mercados de trabajo de los centros españoles empezó siendo sólo un goteo, pero creció sostenidamente durante el siglo xviI, lo cual complicó aún más la tarea de las autoridades de Lima y Madrid a la hora de intentar vigilar y controlar a los corregidores ${ }^{76}$. En consecuencia, los corregidores pudieron enmendar, desoír y dominar la política colonial en las provincias rurales, y utilizar los recursos locales para sus propios fines. En suma, hacia finales del siglo xvi, al disminuir las divisiones entre las élites españolas y el peligro de una revuelta inca, descendió la necesidad de sostener un Estado centralizado fuerte. El resultado fue un aumento constante de prácticas burocráticas corruptas e ineficaces en los corregimientos, lo cual debilitó lentamente la fuerza del Estado creado por Francisco de Toledo durante el período 1580-1630.

"Cole (1984), pp. 37-50; Sánchez-Albornoz (1978), p. 32. 


\section{APENDICE I}

Cálculo de la población tributaria, Caja de Lima, 1580-1630

\begin{tabular}{|c|c|c|c|c|c|c|c|c|c|c|c|c|c|c|}
\hline & & Años & & & & $\begin{array}{c}\text { Total de } \\
\text { tributarios }\end{array}$ & & & $A \tilde{n}$ & ios & & & & $\begin{array}{l}\text { Total de } \\
\text { tributarios }\end{array}$ \\
\hline $\begin{array}{l}1580 \\
1581 \\
1582 \\
1583 \\
1584 \\
1585 \\
1586 \\
1587 \\
1588 \\
1589 \\
1590 \\
1591 \\
1592 \\
1593 \\
1594 \\
1595 \\
1596 \\
1597 \\
1598 \\
1599 \\
1600 \\
1601 \\
1602 \\
1603 \\
1604 \\
1605\end{array}$ & 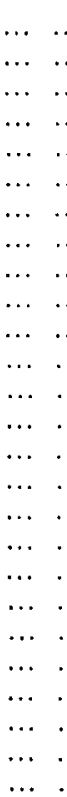 & $\begin{array}{ll}\ldots & \ldots \\
\ldots & \ldots \\
\ldots & \ldots \\
\ldots & \ldots \\
\ldots & \ldots \\
\ldots & \ldots \\
\ldots & \ldots \\
\ldots & \ldots \\
\ldots & \ldots \\
\ldots & \ldots \\
\ldots & \ldots \\
\ldots & \ldots \\
\ldots & \ldots \\
\ldots & \ldots \\
\ldots & \ldots \\
\ldots & \ldots \\
\ldots & \ldots \\
\ldots & \ldots \\
\ldots & \ldots \\
\ldots & \ldots \\
\ldots & \ldots \\
\ldots & \ldots \\
\ldots & \ldots \\
\ldots & \ldots \\
\ldots & \ldots \\
\ldots & \ldots \\
\end{array}$ & $\begin{array}{l}\ldots \\
\ldots \\
\ldots \\
\ldots \\
\ldots \\
\ldots \\
\ldots \\
\ldots \\
\ldots \\
\ldots \\
\ldots \\
\ldots \\
\ldots \\
\ldots \\
\ldots \\
\ldots \\
\ldots \\
\ldots \\
\ldots \\
\ldots \\
\ldots \\
\ldots \\
\ldots \\
\ldots \\
\ldots\end{array}$ & $\begin{array}{l}\ldots \\
\ldots \\
\ldots \\
\ldots \\
\ldots \\
\ldots \\
\ldots \\
\ldots \\
\ldots \\
\ldots \\
\ldots \\
\ldots \\
\ldots \\
\ldots \\
\ldots \\
\ldots \\
\ldots \\
\ldots \\
\ldots \\
\ldots \\
\ldots \\
\ldots \\
\ldots \\
\ldots \\
\ldots \\
\ldots\end{array}$ & $\begin{array}{l}\ldots \\
\ldots \\
\ldots \\
\ldots \\
\ldots \\
\ldots \\
\ldots \\
\ldots \\
\ldots \\
\ldots \\
\ldots \\
\ldots \\
\ldots \\
\ldots \\
\ldots \\
\ldots \\
\ldots \\
\ldots \\
\ldots \\
\ldots \\
\ldots \\
\ldots \\
\ldots \\
\ldots \\
\ldots\end{array}$ & $\begin{array}{l}30.032 \\
29.932 \\
29.470 \\
29.008 \\
28.546 \\
28.084 \\
27.662 \\
27.160 \\
26.698 \\
26.236 \\
25.773 \\
25.408 \\
25.043 \\
24.678 \\
24.313 \\
23.949 \\
23.583 \\
23.219 \\
22.854 \\
22.489 \\
22.124 \\
21.826 \\
21.529 \\
21.234 \\
20.933 \\
20.636\end{array}$ & $\begin{array}{l}1606 \\
1607 \\
1608 \\
1609 \\
1610 \\
1611 \\
1612 \\
1613 \\
1614 \\
1615 \\
1616 \\
1617 \\
1618 \\
1619 \\
1620 \\
1621 \\
1622 \\
1623 \\
1624 \\
1625 \\
1626 \\
1627 \\
1628 \\
1629 \\
1630\end{array}$ & 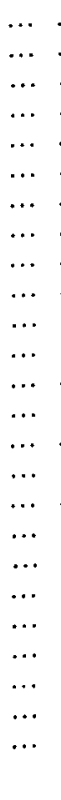 & 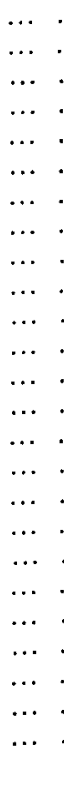 & $\begin{array}{l}\cdots \\
\cdots \\
\cdots \\
\cdots \\
\cdots \\
\cdots \\
\cdots \\
\cdots \\
\cdots \\
\cdots \\
\cdots \\
\cdots \\
\cdots \\
\cdots \\
\cdots \\
\cdots \\
\cdots \\
\cdots \\
\cdots \\
\cdots \\
\cdots \\
\cdots\end{array}$ & 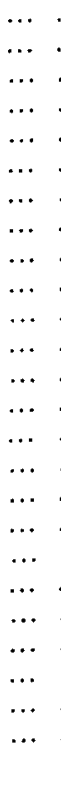 & 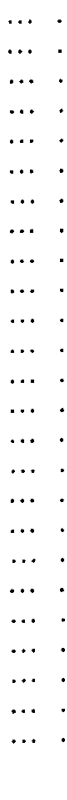 & 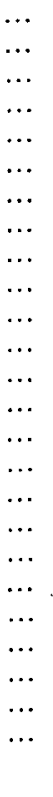 & $\begin{array}{l}20.338 \\
20.040 \\
19.742 \\
19.445 \\
19.147 \\
18.903 \\
18.658 \\
18.414 \\
18.169 \\
17.925 \\
17.681 \\
17.436 \\
17.192 \\
16.947 \\
16.703 \\
16.502 \\
16.300 \\
16.099 \\
15.898 \\
15.697 \\
15.495 \\
15.294 \\
15.093 \\
14.891 \\
14.690\end{array}$ \\
\hline
\end{tabular}




\section{APENDICE II}

Rentas del Ramo de Tributos Reales, Caja de Lima, 1580-1630

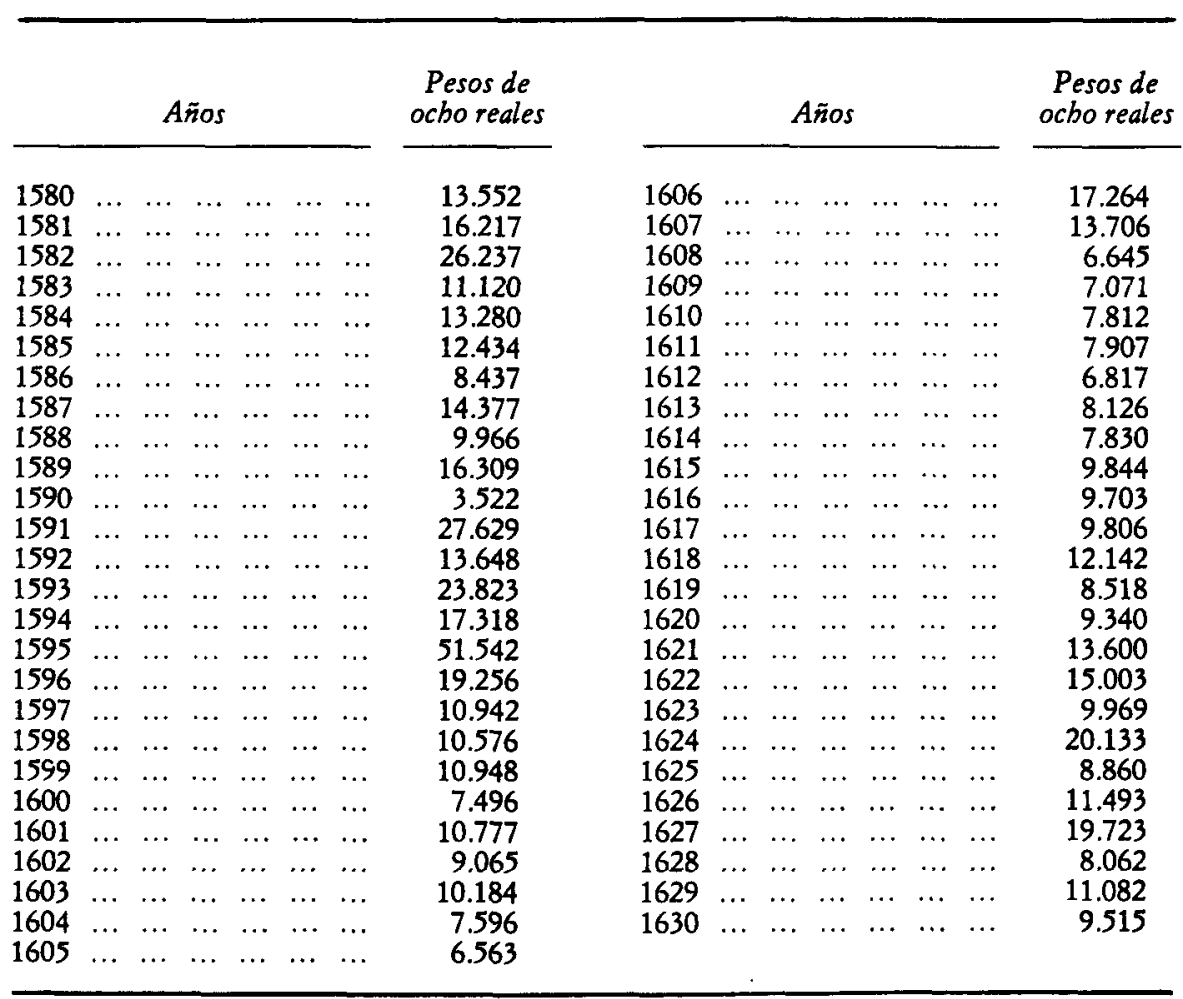




\section{BIBLIOGRAFIA}

ANDRIEN, Kenneth J. (1984): «Corruption, Inefficiency and Imperial Declinew, The Americas, núm. 41, pp. 1-20.

- (1985): Crisis and Decline: The Viceroyalty of Peru in the Seventeentb Century, Alburquerque, University of New Mexico Press.

Ballesteros y Beretta, Antonio (1922-24): Historia de España y su influencia en la bistoria universal, Barcelona y Buenos Aires, Salvat, tomo II.

Barbier, Jacques A. (1972): «Elites and Cadres in Bourbon Chilew, Hispanic American Historical Review, núm. 52, pp. 416-435.

Bora H, Woodrow (1970): «Latin America, 1610-1660», en Cooper, J. P.: The New Cambridge Modern History, Cambridge (Eng.), Cambridge University Press, vol. IV, pp. 707-726.

Cole, Jeffrey Austin (1981): The Potosi Mita Under Habsburg Administration: The Seventeenth Century, $\mathrm{Ph}$. D. Diss., University of Massachusetts.

- (1984): «Viceregal Persistance versus Indian Mobility: The Impact of the Duque de la Palata's Reform Program on Alto Peru», Latin American Research Review, núm. 19, pp. 37-50.

Cook, Noble David (1981): Demographic Collapse: Indian Peru, 1570-1620, Cambridge (Eng.), Cambridge University Press.

- (1973): The Indian Population of Peru, 1570-1620, Ph. D. Diss., University of Texas.

- (1982): «Population Data for Indian Peru: The Sixteenth and Seventeenth Centuries», Hispanic American Historical Review, núm. 62, pp. 73-120.

Escobedo, Ronald (1979): El tributo indigena en el Perú (siglos XVI-XVII), Pamplona, Ediciones Universidad de Navarra.

Evans, Brian (1981): «Census Enumeration in Late Seventeenth Century Alto Peru: The Numeración of 1683-1684», en RobINSon, David: Studies in Spanish American Population History, Boulder (Co.), Westview Press.

FALCón, Francisco (1918): «Representación hecha por el licenciado Falcón en concilio provincial sobre los daños y molestias que se hacen a los indios», en Colección de libros y documentos referentes a la bistoria del Perú, Lima, Imprenta Gil, tomo XI, serie 1, pp. 133-176.

FISHER, John R. (1970): Government and Society in Colonial Peru: The Intendent System, 1784-1814, Londres, Athlone Press.

GiBson, Charles D. (1964): The Aztecs Under Spanish Rule: A History of the Indians of the Valley of Mexico, 1519-1810, Stanford (Ca.), Stanford University Press.

KeIT H, Robert G. (1971): «Encomienda, Hacienda, and Corregimiento in Spanish America: A Structural Analysis», Hispanic American Historical Review, núm. 51, pp. 431446.

Levillier, Roberto (ed.) (1938): Gobernantes del Perú: cartas y papeles del siglo XVI, Madrid, Sucesores de Rivadeneyra, tomo 8.

Lo h MANN Villena, Guillermo (1957): El corregidor de indios en el Perú bajo los Austrias, Madrid, Ediciones Cultura Hispánica.

López de Caravantes, Francisco (1632): «Noticiánen y valor del patrimonio real y sus Tierrafirme, y Chile: El govierno, admin magestad cada año», Madrid, Biblioteca del gastos y lo que da libre y se remit

LyNCH, John (1969): Spain Under the Habsburgs, Oxford (Eng.), Oxford University Press, vol. II, pp. 163-169.

MacLeod, Murdo J. (1982): "The Primitive Nation State, Delegations of Functions and Results: Some Examples from Early Colonial Central Americaw, en SPALding, Karen: Essays in the Political, Economic, and Social History of Colonial Latin America, Newark (Del.), University of Delaware Press, pp. 53-68.

Moreno, Frank J. (1967): *The Spanish Colonial System: A Functional Approach», Western Political Quarterly, núm. 20, pp. 308-320. 
Moreno Cebrián, Alfredo (1977): El corregidor de indios y la economia peruana del siglo XVIII (los repartos forzosos de mercancías), Madrid, Consejo Superior de Investigaciones Científicas.

MoRSE, Richard (1964): «The Heritage of Latin America», en HARTz, Louis: The Founding of New Societies, Nueva York, Harcourt, Brace and World, Inc., pp. 123-177.

PARRY, J. H. (1953): The Sale of Public Offices in the Spanish Indies Under the Habsburgs, Berkeley (Ca.), Iberoamericana.

PhelaN, John Leddy (1960): «Authority and Flexibility in the Spanish Imperial Bureaucracy, Administrative Sciences Quarterly, núm. 5, pp. 47-65.

- (1967): The Kingdom of Quito in the Seventeenth Century: Bureaucratic Politics in the Spanish Empire, Madison (Wi.), University of Wisconsin Press.

Poole, Stafford (1981): «Institutionalized Corruption in the Letrado Bureaucracy: The Case of Pedro de Farfán», The Americas, núm. 38, pp. 149-172.

Ś́nch ez-Albornoz, Nicolás (1978): Indios y tributos en Alto Perú, Lima, Instituto de Estudios Peruanos.

- (1982): «Migraciones internas en el Alto Perú. El saldo acumulado en 1645», Historia Boliviana, núm. 1, pp. 11-19.

Santillán, Fernando (1965): "Relación del origen, descendencia, política, y gobierno de los Incas», en JIMÉNEz DE LA ESPADA, Marcos: Relaciones geográficas de Indias, Perú, Madrid, Editorial Atlas, tomo II.

SarfatTr, Magali (1966): Spanish Bureaucratic Patrimonialism in America, Berkeley (Ca.), University of California Press.

SCH wartz, Stuart (1970): «Magistracy and Society in Colonial Brazil», Hispanic American Historical Review, núm. 50, pp. 715-730.

Solórzano y Pereyra, Juan (1972): Politica Indiana, Madrid, Editorial Atlas.

SPAlding, Karen (1982): Essays in the Political, Economic, and Social History of Colonial Latin America, Newark (Del.), University of Delaware Press.

- (1975): De indio a campesino: cambios en la estructura social del Perú, Lima, Instituto de Estudios Peruanos.

- (1983): Huarochiri: An Andean Society Under Inca and Spanish Rule, Stanford (Ca.), Stanford University Press.

Stern, Steve J. (1982 a): Peru's Indian Peoples and the Challenge of Spanish Conquest: Huamanga to 1640, Madison ( $\mathrm{Wi}$.), University of $\mathrm{W}$ isconsin Press.

- (1982 b): *The Social Significance of Judicial Institutions in an Exploitative Society: Huamanga, Peru, 1570-1640», en Collier, George A.; Rosaldo, Renato I., y WIRT H, John D.: The Inca and Aztec States, 1400-1800, Nueva York, Academic Press, pp. 289320.

TE PAske, John J., y KLEIN, Herbert S. (1982): The Royal Treasuries of the Spanish Empire in America, Durham (N. C.), Duke University Press, 3 vols.

Toledo, Francisco de (1921): «Libro de la Visita General del Virrey Don Francisco de Toledo, 1570-1575», Revista Histórica, núm. 7, pp. 118-200.

Torres Saldamando, Enrique (1967): Apuntes bistóricos sobre las encomiendas del Perú, Lima, Universidad Nacional de San Marcos.

Tomás Y ValiEnTE, Francisco (1972): La venta de oficios en Indias (1492-1606), Madrid, Instituto de Estudios Administrativos.

VAzquez, Mateo (1842-95): «Memorial del Perú de las cosas del Perú tocantes a los indios al muy ilustre señor Mateo Vázquez», Colección de documentos inéditos para la historia de España, Madrid, M. Ginesta Hermanos, Impresores de la Real Casa, tomo 94, pp. 554-597.

Yalf Román, Alberto (1974): «Sobre Alcaldías Mayores y Corregimientos en Indias: Un ensayo de interpretación», Jabrbucb für Geschicbte von Staat, Wirtschaft, um Gesellschaft Lateinamerikas, núm. 9, pp. 1-39.

Zavala, Silvio (1973): La encomienda indiana, México, Editorial Porrúa. 